\title{
Dino Bueno*.
}

\author{
J. J. Cardozo de Mello Neto \\ Professor Emérito da Faculdade de Direito \\ da Universidade de São Paulo.
}

A Congregação dos Professôres da Faculdade de Direito de São Paulo, pela voz daquele que, por tê-lo conhecido pessoalmente e por si e pelos seus com êle privado, foi o preferido, reservou esta noite para relembrar, como lição, a existência do Prof. Antonio Dino da Costa Bueno, cujo centenário de nascimento ora se comemora.

Surgiu para a vida, só, sem ajuda, mas com um programa.

Realizou-o. Foi assim um exemplo de tenacidade. A vitória de uma vontade.

Ei-lo, nesta Casa, menino, aos 16 anos, modesto, aplicado, contando consigo mesmo e mais ninguém.

Entra discretamente. Já, no $2 .^{\circ}$ ano, porém, dentre as provas escritas surge uma, com a nota — ótima - a única da época.

Seria a de algum dos estudantes de brilho acadêmico, que tantos havia naquele tempo, oradores e poetas, futuros juristas de pról? Não.

Era um jovem filho de Pindamonhangaba, cujo nome pela primeira vez se ouviu nas Arcadas para, de então em diante, nelas perenemente ressoar.

Esta nota e a conseqüente distinção, no exame oral, constituiram, fora de dúvida, aquelas por êle mesmo referidas "circunstâncias acadêmicas, ocorridas no decurso do

* Discurso pronunciado em sesão solene da Faculdade de Direito, por ocasião do primeiro centenário do nascimento do Prof. Dino Bueno, ocorrido em dezembro de 1954. 
meu segundo ano de estudos, que deixaram assentado no meu espírito o propósito firme e decidido de conquistar, pelo meu esfôrço, o grau de doutor e, em seguida, uma cadeira de lente na Faculdade de Direito".

E continua: "Eu havia assentado êsse propósito, quando apenas iniciava os meus dezesete anos de idade". Sem família valorosa, sem recursos, dificílimo seria realizá-lo; mas a minha sorte estava lançada - "alea jact est", e, para ela, eu só podia contar com o meu esfôrço. Estudei para isso e para isso encaminhei minha vida".

Logo no ano seguinte, já promotor público da Capital, defende teses e é aprovado unânimemente.

Sua satisfação sente-se nessa simples anotação: "No dia 9 de novembro de 1876, (um ano após a formatura) tive a honra especial de sentar-me no doutoral da Faculdade, logo abaixo do lente mais novo - Dr. Joaquim Augusto de Camargo.

No ano seguinte, inscreve-se à vaga de substituto. E habilitado, mas a nomeação cabe a LeITE Morars.

Em 1882, abrem-se quatro concursos. Dino BuEno em todos se inscreve e concorre a três.

No primeiro, a classificação cabe a JoÃo MonTEIRo, mas o nomeado é Vicente Mamede.

No segundo, é nomeado JoÃo MonteIro, novamente classificado em $10^{\circ}$ lugar.

Ao terceiro não se apresenta.

Ao quarto concorre com Brasilio Machado e Lopes Dos Anjos.

Classificado em 1. ${ }^{\circ}$ lugar, é nomeado.

Três concursos no espaço de doze meses! Só quem por essas provas passou pode avaliar a intensidade do esfôrço intelectual e físico daquele moço que, ao estudo, teria de acumular o trabalho de Promotor Público da Capital.

Mas, o que nos deixou admirado, ao termos à vista as provas dos sucessivos concursos, foi o patente progresso dos estudos do candidato. 
Suas dissertações são tôdas bem lançadas. Nenhuma divagação; a matéria e sòmente ela. Mas, só a última é que dá a medida do que iria ser o futuro lente de Direito Civil. A adoção que efeitos produz entre nós, atualmente? de uma perfeita segurança de doutrina é exposta com aquela clareza que, aperfeiçoada pelo uso da cátedra, fêz de DiNo BuENo, sem contestação, o professor de mais marcada capacidade didática do seu tempo.

A data da promoção de Drno Bueno a lente Catedrático (1890), coincide com a formação da que, com justiça, podemos chamar - Grande Congregação.

Se, no passado, iluminaram a Cátedra Crispiniano. Carrão, Ribas, José Bonifácio, o Moço, Justino, Duarte de Azevedo, Dutra Rodrigues, foram êsses, no entanto, individualidades isoladas que salpicaram a Congregação no espaço dilatado de sessenta anos.

A época áurea foi aquela que se me apresentou aos olhos assombrados de $10^{\circ}$ anista.

O venerando RamalHo, de 90 anos, presidindo um concurso em que julgavam João Monteiro, Brasílio Machado, Dino Bueno, Joño Mendes Junior, Pedro Lessa, Escorel, Almeida Nogueira, Herculano de Freitas, Pinto Ferraz, Amâncio de Carvalho, Manuel Vilaboim, Camargo Aranha, Gabriel de Rezende, Reinaldo Porchat, Cândido Mota, José Ulpiano, Oliveira Coutinho, Alcântara Machado, Dario Ribeiro.

Dentre essa plêiade, Dino BuEno estava na primeira linha.

Respeitado pelos colegas, admirado e amado pelos seus discípulos, demos a palavra a um dos maiores dêles, que também foi dos maiores entre nós: Frederico Vergueiro SteIDel que, falando em nome da Congregação, no ato da posse do diretor, assim se expressou:

"Vós que o ouvis diàriamente, na sua Cátedra de Direito Civil, que êle tanto eleva, sabeis quão clara, convincente e amena é a sua palavra, e conheceis tão bem como eu que, como tantos outros lentes da atual Congregação, ti- 
vemos a honra de ser seus discípulos, os seus inestimáveis dotes de Professor, claro na exposição, metódico ao desenvolver os assuntos, profundo nos conceitos que emite e assíduo nos seus trabalhos. A admiração que inspira a figura circunspecta do nosso Diretor estende-se fora dos muros dêste velho Convento".

Mais tarde, 40 anos depois de ter ouvido do Dr. Dino a primeira aula de Direito, Frederico Steidel promove a comovedora repetição de uma lição do Mestre.

"Sem o auxílio de uma nota, com voz cristalina, Dino Bueno recordou a preleção de Direito Natural com que se despediu da turma e que versava sôbre as funções do Estado. Agigantou-se na Cátedra e mostrou que ainda era o mesmo extraordinário Professor, de tantas gerações, o didata por excelência, cuja palavra tinha a limpidez da água da fonte" (Conferência de GontiJo de CarvalHo na Universidade de Minas Gerais).

Em 1908, ascende Dino Bueno à diretoria da Faculdade, onde se conserva durante quatro anos.

Fazia exatamente dezoito anos que não se pregava um prego na Academia, não se caiava uma parede - quasi tôdas esburacadas. Não se comprava um banco escolar. Não se cuidava da biblioteca. Sob o aspecto material, tudo era uma lástima.

Isso após a diretoria do conselheiro PADUa Fleury, sob cuja direção o convento tomou o aspecto que manteve até sua demolição. Na proveitosa administração dêste, foram abertas as três portas de frente do prédio (anteriormente a entrada era pela Igreja de São Francisco), construídas as escadas laterais que levavam ao $2 .^{\circ}$ andar, melhorada a Biblioteca e o mobiliário, que ainda assim permaneceu de uma pobreza franciscana.

O novo diretor tem, como sempre, um programa e vai executá-lo.

Começa por reincorporar a parte reservada ao extinto Curso Anexo, que estava inteiramente abandonada, às comodidades da Academia: eram mais quatro salas de aula que 
surgiam. Moderniza, pela primeira vez, o mobiliário que, no nosso tempo, consistia em bancos de madeira para cinco estudantes. Surgem as primeiras cadeiras isoladas. Faz obras completas de pintura e conservação. Manda construir a Sala da Congregação por sôbre a Sacristia do Convento dotando-a de mobiliário apropriado e considerado até luxuoso para a época. Dantes a Congregação reunia-se em torno de uma mesa comprida, com o Diretor na cabeceira. Reforma integralmente o salão nobre, que toma aspecto majestoso. Cria a galeria dos diretores. Restaura a ordem na Biblioteca. Impõe a disciplina entre os funcionários. Suavemente, antes pelo exemplo do que por palavras, torna mais freqüentes os alunos e... os colegas.

Ao Conselheiro Fleury e a Dino Bueno ficou devendo esta Casa o confôrto mínimo que os estudantes e lentes tiveram antigamente, único cabivel diante da mesquinhez das verbas federais. Como a Alcântara Machado, dentre os mortos, deve a geração presente o ambiente de bem-estar e de convite ao estudo que o novo convento oferece.

Os homens do Direito, no Brasil, ao tempo do Dr. Dino Bueno, jamais se insularam na atividade privada. Jamais se limitaram os advogados a advogar, os lentes a ensinar. A natureza de sua atividade, que os levava a agir dentro da sociedade, que o Direito preside, criou neles o espirito público que se manifesta pela ação política, tornada assim função normal do bacharel de Direito.

A essa regra, não constituíu exceção o Dr. Dino Bueno. Ao contrário, foi desde os bancos acadêmicos um político no alto sentido do têrmo. Nasceu político, viveu dentro da política, e político morreu.

Filiado ao grande e forte Partido Conservador, a êle se manteve fiel até sua extinção na república.

Dedicou-se, desde logo, à sua cidade natal - a querida Pindamonhangaba, que nunca esqueceu, à qual doou bens materiais valiosos, à qual serviu pela assistência contínua e direção permanente da política local. 
Tendo, com seus companheiros do Partido Conservador, aderido à República, alçou-se até a presidência do Partido Republicano Paulista.

Secretário do Interior na presidência Campos SALES: deputado federal em 1894, voltou à câmara, onde teve assento em 1900 e 1901, também no govêrno Campos Sales, como lider da maioria.

Sua atuação em defesa do govêrno do grande paulista foi decisiva e, ainda hoje, é relembrada.

Sua reconhecida aptidão juridica foi aproveitada na comissão revisora do Código Civil, como mais tarde o seria na elaboração do projeto do Código do Processo do Estado de São Paulo.

Preferindo permanecer em São Paulo, para não abandonar o ensino nesta nossa e sua casa, foi eleito senador estadual em 1904 e no Senado permaneceu até 1930 .

Durante um quarto de século o Dr. DrNo Bueno repartiu sua atividade entre a Academia e o Senado.

Foram por certo os mais belos anos de sua existência, porque transcorridos dentro da vitória. Com o tempo, tornou-se o oráculo daquele ramo do poder público estadual, ao qual ficamos devendo o equilíbrio na legislação e na política, que contribuíu, em magna parte, para $o$ respeito por São Paulo no seio da Federação.

Membro permanente da Comissão de Recursos Municipais e dela relator nos mais espinhosos casos, contribuíu com suas luzes e experiência para, em sentenças, que no fundo o eram as decisões proferidas, conter o Senado tanto as demasias das Câmaras Municipais como as do próprio Poder Executivo.

Aparentemente frio, ao primeiro contacto sentia-se, com o convívio, que a atitude era apenas uma defesa, para não deixar transbordar o coração.

Disso tivemos a prova num incidente que peço venia para relembrar.

O senador Raul Cardozo de Mello relatava, em memorável discurso, a inominável violência de que tinha sido 
vítima por parte de certas autoridades no decurso da revolta de 1924 quando, em determinado momento, com voz impossível de definição, exclámou: "Aqui tem o Senado (exibindo uma corda) para sua edificação e da nossa civilização, a corda com que fui amarrado".

As fisionomias dos senadores crisparam-se. Os olhares se fixaram na mesa: o presidente do senado chorava.

O coroamento da vida pública do Prof. Dino Bueno realizou-se quasi no fim de sua existência, ao assumir, como presidente do senado, a presidência do Estado.

Pena foi que não a houvesse exercido, num quadriênio próprio e na plenitude de suas fôrças. Êle a merecera e mais ainda São Paulo, para sua grandeza.

Relembrada está a vida de Antônio Dino da Costa Bueno, repartida, como se viu, entre a Academia, que êle teve sempre no coração, e o Brasil, a quem serviu pela inteligência, sem jactância; pela austeridade, sem ostentação.

Um dia, Dino Bueno pediu a seus netos que lhe oferecessem um estandarte da Faculdade de Direito e, aos filhos, uma bandeira nacional; ambos em miniatura, um e outro em sêda e bordados a ouro.

Só no dia da morte se soube para que os queria. Eu os vi, comovido: o estandarte da Academia, sôbre o coração; a Bandeira Nacional, sôbre a cabeça. 